\title{
Determinants of attitude and intention towards private health insurance: a comparison of insured and uninsured young adults in Australia
}

\author{
Lisa $\operatorname{Tam}^{1 *}$ (D) Ellen Tyquin ${ }^{1}$, Amisha Mehta ${ }^{1}$ and Ingrid Larkin²
}

\begin{abstract}
Background: Since the introduction in 1984 of Australia's publicly-funded universal healthcare system, Medicare, healthcare financing has relied on a mix of public and private sources to meet the needs of the population (Sowa et al., Appl Health Econ Health Policy 15:31-41, 2018). However, in recent years, there has been a decline in the number of Australians choosing to purchase private health insurance (PHI), particularly within the young adult age group with the proportion of insurance customers aged 20 to 29 falling from 10.3 to 9.4\% between 2012 and 2017 (Sivey, The Conversation, 2017). Young adults are critical to private health insurance funding models as their involvement offsets the drawdown by older adults (Dalzell and Borys, ABC News, 2019). While this issue is widely reported in the Australian media, few empirical studies have explored the factors that enable or constrain young adults' enrolment in $\mathrm{PHI}$.
\end{abstract}

Methods: To address the scarcity of research about the motivational factors behind young adult decision-making, this study conducted a survey of 594 Australian young adults aged between 18 and 30 years. Within this age group, the survey sought an equal split of participants who were members and non-members of PHI schemes.

Conclusion: The findings identified perceived value and trust in insurers as additional motivational factors alongside traditional measures of recognition of the problem and involvement in the problem. Differences between the insured and uninsured groups were identified which help to shape a more holistic understanding of the key motivational factors and barriers in relation to Australian young adults' enrolment in PHI.

Keywords: Australia, Private health insurance, Trust, Value, Young adults

\section{Background}

Private health insurance (PHI) has been a significant social and policy issue that has received extensive coverage within the Australian media [1] primarily due to its cost [2] and complexity to comprehend [3]. Despite Australia's publicly-funded universal healthcare scheme, Medicare,

\footnotetext{
* Correspondence: I.tam@qut.edu.au

${ }^{1}$ School of Advertising, Marketing and Public Relations, Queensland University of Technology, 2 George Street, Brisbane, QLD 4000, Australia Full list of author information is available at the end of the article
}

which all Australians have access to and most taxpayers contribute $2 \%$ of their taxable income to fund, PHI still remains an important component of healthcare funding [4]. According to official statistics released in March 2020, $43.80 \%$ of the Australian population was voluntarily enrolled in PHI [5]. However, there has been a downward trend. For example, between December 2019 and March 2020 there has been a 0.2 percentage point decrease in enrolment, with the largest net decrease (11,176 people) in the age group between 25 and 29 [5]. This presents a

C C The Author(s). 2021 Open Access This article is licensed under a Creative Commons Attribution 4.0 International License, which permits use, sharing, adaptation, distribution and reproduction in any medium or format, as long as you give appropriate credit to the original author(s) and the source, provide a link to the Creative Commons licence, and indicate if changes were made. The images or other third party material in this article are included in the article's Creative Commons licence, unless indicated otherwise in a credit line to the material. If material is not included in the article's Creative Commons licence and your intended use is not permitted by statutory regulation or exceeds the permitted use, you will need to obtain permission directly from the copyright holder. To view a copy of this licence, visit http://creativecommons.org/licenses/by/4.0/ The Creative Commons Public Domain Dedication waiver (http://creativecommons.org/publicdomain/zero/1.0/) applies to the data made available in this article, unless otherwise stated in a credit line to the data. 
growing concern for both the Australian government and healthcare sector as young adults are critical to the PHI system because they improve the risk pool [6]. The departure of healthy young adults from the PHI system has the power to impact the wider Australian health system as it increases the premiums paid by older people for PHI and puts pressure back onto the public health system [7].

Existing research on PHI in Australia has been driven from an economic perspective, focusing on the effectiveness of government initiatives to incentivise and reduce barriers to enrolment in PHI [4, 8-11]. It is compulsory for most Australian taxpayers to pay an annual Medicare Levy to fund the public health system and single people earning above $\mathrm{A} \$ 90,000$ or families earning above A $\$ 180,000$ have to pay an additional Medicare Levy Surcharge (MLS) if they do not have PHI. In addition to this MLS, individuals aged 31 or above have to pay a $2 \%$ Lifetime Health Cover loading on their health insurance premiums for every year they go without hospital cover [10]. Further incentive to enrol in PHI by the Australian government is offered through age-based rebates on PHI premiums (ranging from approximately 8 to $33 \%$ ) to encourage early enrolment in PHI [9]. Despite these economic levers, the acceleration of dropouts in PHI (from $47.4 \%$ in 2015 to $43.8 \%$ in 2020 ) suggests that economics alone does not explain the full story of why individuals choose to enrol in PHI [5]. As such, there is a need to examine wider motivational factors and barriers to enrolling in and maintaining PHI [11].

With this backdrop, this study proposes to examine the factors that affect young adults' attitude and behavioural intentions toward PHI. The purpose of this study is three-fold: (1) to explore the attitudinal and motivational differences between young adults (aged 18-30 years) with and without PHI; (2) to identify the factors that motivate those without PHI to enrol in PHI; and (3) to examine the factors that motivate those with PHI to cancel PHI. Specifically, this study will compare the two groups (i.e., those with and those without PHI) in terms of their health consciousness, perceptual variables (e.g., problem recognition, constraint recognition, involvement recognition, past experiences), trust, perceived value, attitude and intention to enrol/cancel. The examination of the dynamics of these factors will provide a more holistic framework that seeks to explain variations in attitude and behavioural intentions toward PHI.

\section{Factors affecting PHI choices in Australia}

Research on PHI in Australia to date has focussed on three perspectives: (i) policy levers, and (ii) individual risk, and (iii) promotion of PHI. First, on the policy side, there has been a series of PHI policy reforms that sought to increase uptake in PHI as referenced above. A 2007 study found the Medicare Levy Surcharge, premium rebates and Lifetime Health Cover Loading all had a positive effect on the uptake of PHI, but the magnitude of the effects was not easily untangled [10]. Conversely, another study found that these reforms only benefited those who would have purchased PHI regardless of policy levers rather than encouraging those who did not intend to enrol [9].

Second, an individuals' decision to purchase PHI has been examined from a risk perspective. Given that health insurers are prohibited from adjusting premiums based on consumer risk (e.g., pre-existing conditions), a positive correlation between insurance uptake and expected claims can be expected, however data has shown that those with PHI actually spent fewer nights in hospitals [12]. Even though it was expected that individuals with poor health were more likely to purchase PHI due to their anticipation of the need of medical care, they were outnumbered by healthier consumers who had higher risk aversion [12].

Third, studies have begun to explore how organisations promoted PHI. A study of insurers' websites found that health insurers promoted choice and healthy lifestyles as the benefits of PHI, suggesting this positioning was an effective marketing strategy [13]. Furthermore, a study of Australian health consumers found that consumers' choices are not grounded in their individual experiences of the system but their futuristic expectations of benefit and whom they trust to help them minimise risk [14]. In the United States, factors including perceived health status, perceived value, perceived need, socioeconomic status and ethnicity significantly affected whether U.S. young adults would enrol in PHI and that there was a combination of factors that affected their choices [15].

Despite changes in policies that seek to encourage Australians into the PHI system and remove pressure on the public system and an expectation that due to risk aversion consumers would be motivated to maximise PHI utility [13], many Australians still choose to 'ditch' or refuse to enrol in PHI. This environment surrounding the PHI system points to the need to explore a new question. Instead of focusing on the economic reasons for why people, especially young people, do not take out PHI, we need to examine the motivational factors and barriers that explain young adults' attitude and behavioural intentions toward PHI amongst those who have and who do not have PHI. Those with and without PHI may not use the same decision-making models. As such, this study seeks to contribute to knowledge on this topic by reviewing motivational factors that may explain young adults' attitude and behavioural intentions toward PHI. This study will focus on young adults aged 18-30 in Australia because of their importance in balancing the risk pool [6]. Particularly, the following variables are 
examined and explained in the following sub-sections: health consciousness, perceptual variables (i.e., problem recognition, involvement recognition, constraint recognition, past experiences), trust, perceived value and attitude and intention to purchase/cancel PHI.

\section{Health consciousness}

Individuals who have high health consciousness have been found to take greater responsibility for protecting their own health by complying with health-related recommendations [16], and adopting healthy behaviours $[17,18]$ such as maintaining a healthy diet $[19,20]$ and getting regular exercise [21]. Existing literature in health communication has found that individuals with higher levels of health consciousness (i.e., the extent to which health concerns are integrated into a person's daily activities) are more likely to display intentions to search for health-related information [22, 23]. These studies have also shown that these individuals actively seek out health information and use more information sources than those who are not health-oriented [17]. Given the focus of current and future-oriented health behaviours noted in studies around health consciousness, this study proposed the following hypothesis:

H1o: Australian young adults with and without PHI show no statistical difference in health consciousness.

\section{Perceptual factors}

Existing research on PHI has examined individuals' choices as being confined by policies, their individual evaluations of risk [14] and the maximisation of utility [24]. However these perspectives are based on decisionmaking theories that assume perfect and equal knowledge amongst individuals who maximise utility/ satisfaction.

However, communication theories [24-26] criticise the assumption of perfect knowledge, arguing that knowledge and information is neither free nor given in decision situations. Instead these communication-based theories proport that when confronting a problem, individuals become engaged in communicative behaviours (e.g., information acquisition and transmission) that help them obtain the information and knowledge in order to make a decision. In the context of health, four variables in the Situational Theory of Problem Solving - problem recognition, constraint recognition, involvement recognition and referent criterion - have been used to predict individuals' engagement in health-related communicative behaviours [27-31]. The theory presents the argument that when individuals perceive the presence of a problem (e.g., the need for PHI), feel connected to the problem, and see few obstacles in solving the problem, they will be engaged in behaviours to solve the problem. It has been previously used to guide understanding on motivations to act on health issues such as weight loss and organ donation [26, 32, 33].

Building on the Situational Theory of Problem Solving [26], this study proposes to examine four variables as possible perceptual factors that differentiate young adults with and without PHI. First, problem recognition is defined as an individual's perceptions of a discrepancy between the expected state and the experiential state (e.g., perceptions of lack of PHI as a problem). Second, involvement recognition is defined as the connection between oneself and the problem (e.g., one's being personally affected by not having PHI). Third, constraint recognition refers to the perceptions of obstacles that limit one's ability to solve the problem (e.g., the lack of resources to solve the problem). Lastly, referent criterion, generally referred to as past experiences that guide one's approaches to solving the problem, is operationalised as one's past experiences with PHI. Accordingly, the following hypothesis is proposed:

H2o: Australian young adults with and without PHI show no statistical difference in their (a) problem recognition, (b) constraint recognition, (c) involvement recognition and (d) past experiences with PHI.

\section{Perceived value}

Previous literature indicates that people are more likely to invest in health insurance if they perceive the benefits exceed the out-of-pocket costs [15]. A U.S. study found that the rising cost of insurance premiums is a major reason why so many young adults do not purchase PHI [15]. This sentiment can be reflected within Australia, with significant rises in premium costs [34]. While cost is not an element that communicators are able to change, the concept of perceived value is worth addressing. Currently it can be argued that many young adults' perceived value of PHI does not outweigh its cost. In support of this, the U.S. study found that while individuals' perception of health insurance's value (worth or not worth the cost) was not significantly correlated with the likelihood of having health insurance in their 2005 sample, perceived value was a statistically significant variable in 2008 [15]. Thus, the following hypothesis is proposed:

H3o: Australian young adults with and without PHI show no statistical difference in their perceived value of PHI.

\section{Trust}

Trust has been the subject of many empirical studies and has been found to be an important factor in cultivating long-term, positive relationships between an 
organisation and its strategic stakeholders [35], enhancing customer loyalty [36], gaining positive word-ofmouth recommendations [37] and increasing purchase intention [38]. In the PHI context, an exploratory, qualitative study investigated the motivations for the uptake of PHI in young Australians [14]. It noted that reasons for health insurance decision-making did not reflect a "rational or calculative" approach (p. 399). The authors found that young adults rely less on evidence (such as their PHI contract or previous experience) than they do on trust in the system [14]. As a result the paper suggests people do not calculate the possibilities of ill health, or weigh up the costs and benefits of private and public provision of health care [14], instead they rely on more of an emotive response to purchasing PHI. Building on the findings of this study, we intend to incorporate trust in PHI providers as a key element of this study to determine its potential impact on PHI decision making with the following hypothesis:

H4o: Australian young adults with and without PHI show no statistical difference in their trust in insurance companies.

\section{Attitude}

While the perceptual factors (i.e., problem recognition, constraint recognition, involvement recognition, past experiences), perceived value and trust have been identified as possible factors that characterise the differences between those with and without PHI in previous research, this study follows other behaviour-related literature in positing the dynamics amongst perceptions, attitude and behavioural intentions/behaviours [39]. The Theory of Planned Behaviour suggests that there are relations among beliefs, attitude, intentions, and behaviours [40]. Attitude is defined as "the degree to which a person has a favourable or unfavourable evaluation or appraisal of the behaviour in question" (p. 188), and the formation of attitude is dependent upon perceptual variables and beliefs which are associated with the intentions of performing the behaviours [41]. Thus, this study proposes that those with and without PHI would differ in terms of their attitude and that the identified variables would affect individuals' attitude toward PHI.

H5o: Australian young adults with PHI and without PHI show no statistical difference in their attitude toward PHI.

H6o: (a) Problem recognition, (b) constraint recognition, (c) involvement recognition, (d) perceived value, and (e) trust have no statistically significant relationships with attitude toward PHI.

\section{Intention to enrol/cancel PHI}

Following the models which explain the dynamics amongst perceptions, attitude and behavioural intentions, this study posits that there are relationships between past experiences and behavioural intentions to cancel (for those with PHI) and to enrol (for those without PHI). This proposition is based on theory that suggests positive attitude toward a behaviour strengthens an individual's intention to perform the behaviour under consideration [40]. Accordingly this study proposes that attitude will have a positive effect on intention to enrol (for those without PHI) and a negative effect on intention to cancel (for those with PHI). The following hypotheses are proposed.

H7o: Past experiences have no associations with (a) intention to enrol (for those without PHI) and (b) intention to cancel (for those with PHI).

H8o: Attitude has no associations with (a) intention to enrol (for those without PHI) and (b) intention to cancel (for those with PHI).

Figure 1 shows a proposed model with Hypotheses 68.

\section{Methods}

\section{Measures}

An online questionnaire was developed to explore the dynamics of the variables and to test the hypotheses. First, the survey items were all adopted from existing studies, including health consciousness (five items) [22], the four perceptual variables (i.e., four items for problem recognition, constraint recognition, involvement recognition and past experience each) [26], perceived value ("I do not think I can get my value for money from private health insurance") [15], trust (six items) [42], attitude (four items) and behavioural intentions ("I intend to cancel my private health insurance" or "I intend to sign up for private health insurance in the future") [40].

\section{Data collection and demographics}

Upon approval from the University's ethics committee, Survey Sampling International (SSI, now known as Dynata) was commissioned to recruit two groups of Australian young adults (aged 18-30 years) to complete a 15-min online questionnaire. Participants were recruited to be representative of the Australian population in terms of age and gender in the selected age range. The 18-30 age range was selected because their premiums were not affected by the Lifetime Health Cover Loading [10]. Despite their importance in improving the risk pool of PHI, there are no policy incentives (e.g., increased costs) which affect their intention to enrol or cancel. The downward trend in this age group's 


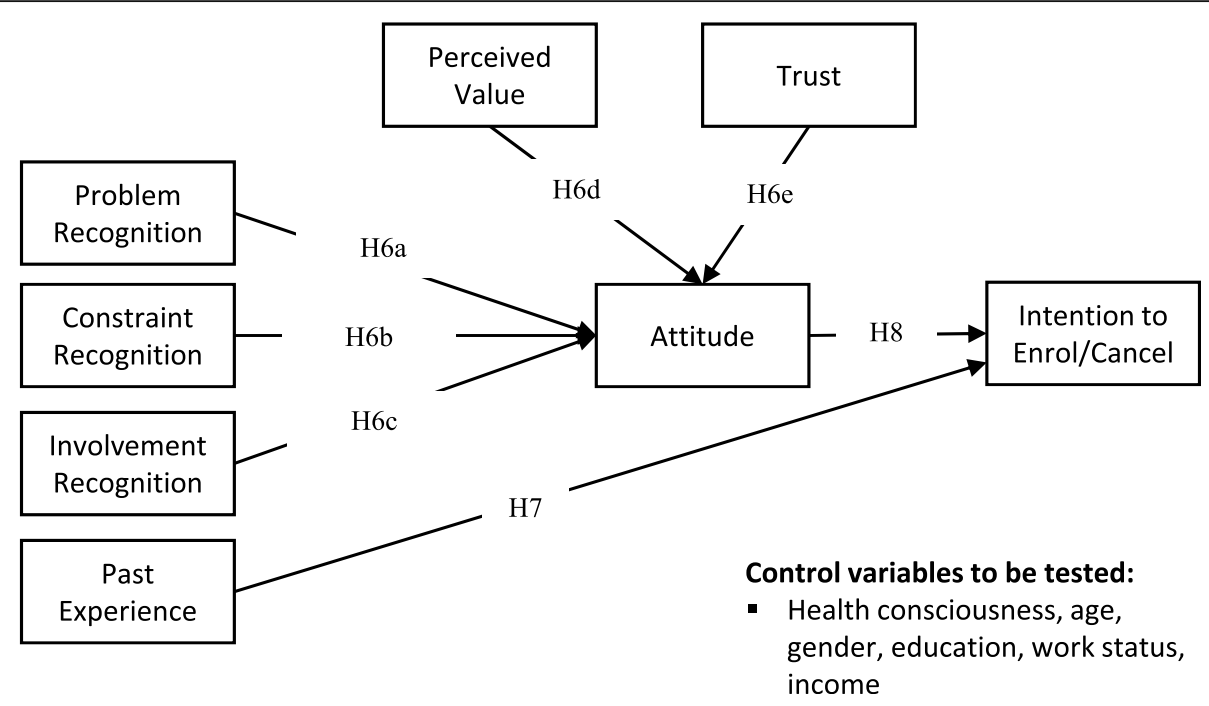

Fig. 1 Hypothesised model to be tested

enrolment in PHI warrants further investigation into other factors which affect their motivations to enrol or to cancel PHI [5]. The participants were incentivised for their time based on their agreements with SSI. A total of 583 valid questionnaires were received in April 2018. Of this total sample, $282(48.4 \%)$ respondents had PHI and 301 (51.6\%) respondents did not have PHI. Table 1 shows a breakdown of demographics of the two groups.

Because SSI was instructed to obtain comparable samples by age and gender for those with and without PHI, the two groups did not differ in terms of age and gender. But for educational attainment, there is a significant difference $(\mathrm{F}=6.8, \mathrm{df}=5, p<.001)$ with a post-hoc test showing significant difference between those with high school education and masters and doctorate $(p<.001)$. The latter is more likely to have PHI. Significant differences were also found for paid work status $(\mathrm{F}=12.816$, $\mathrm{df}=5, p<.001)$. The post-hoc tests showed that the "unemployed" group was the least likely to have PHI and was significantly different from those with full-time work $(p<.001)$ and part-time work $(p<.001)$ who were the most likely to have PHI. Lastly, significant differences were also found for income $(\mathrm{F}=13.142, \mathrm{df}=5, p<.001)$. The post-hoc tests showed a positive relationship between levels of income and PHI status. The higher the income, the higher the likelihood of having PHI.

\section{Data analysis}

Before proceeding with hypotheses testing, items for constraint recognition which were positively worded were first reverse-coded. Then, Exploratory Factor Analysis (EFA) using Maximum Likelihood with Promax Rotation [43] was conducted on the survey items used for each variable (which is evaluated using a five-point
Likert scale from "strongly disagree" to "strongly agree") using SPSS (Statistical Package for the Social Sciences) Version 25. This ensures the latent structure of the observed variables [44], which was needed because the items were adopted from existing research studies but were applied to a PHI context. Table 2 shows the factor loadings, the mean standard deviation (SD) and standard error (SE) of the mean for each item that was retained. Items with factor loadings of less than .6 were removed. The factor loadings of retained items ranged from .634 to .904 . The Cronbach alpha $(\alpha)$ ranged from .743 to .931. The Kaiser-Meyer-Olkin (KMO) measure of adequacy for each variable ranged from .693 to.904. The Bartlett's test of sphericity was significant for all variables. The variance explained ranged from 61.53 to $78.85 \%$. The eigenvalues of all retained factors were all above 1 . The EFA indicated that the retained items were adequate to explain the latent variables [45]. After confirming the dimensionality of each construct, a Confirmatory Factor Analysis (CFA) was conducted for each construct to identify the factor weights for creating the composite scores for testing the hypotheses on SPSS and AMOS. Subsequently, Hypotheses 1-5 were tested using t-tests and ANOVAs to test the differences between those with and without PHI. Structural Equation Modelling (SEM) was performed to test Hypotheses 6-8.

\section{Results}

Table 3 shows the results from the hypothesis testing.

$\mathrm{H} 1$ examined whether those with and without PHI are significantly different in terms of their health consciousness (measured using three formative items with a fivepoint Likert scale). T-test results showed statistical differences between the two groups for health 
Table 1 Demographics of the respondents

\begin{tabular}{|c|c|c|c|}
\hline & $\begin{array}{l}\text { With PHI } \\
n=282(48.4 \%)\end{array}$ & $\begin{array}{l}\text { Without PHI } \\
n=301(51.6 \%)\end{array}$ & Statistical difference \\
\hline \multicolumn{4}{|l|}{ Gender } \\
\hline Male & $130(46.1 \%)$ & $116(38.5 \%)$ & \multirow[t]{3}{*}{ No difference due to sample requirements } \\
\hline Female & $151(53.5 \%)$ & $184(61.1 \%)$ & \\
\hline Prefer not to say & $1(.4 \%)$ & $1(.3 \%)$ & \\
\hline \multicolumn{4}{|l|}{ Age } \\
\hline $18-20$ & $30(10.6 \%)$ & $46(15.3 \%)$ & \multirow[t]{3}{*}{ No difference due to sample requirements } \\
\hline $21-25$ & $222(78.7 \%)$ & $106(35.2 \%)$ & \\
\hline $26-30$ & $30(10.6 \%)$ & $149(49.5 \%)$ & \\
\hline \multicolumn{4}{|l|}{ Education } \\
\hline Primary school & $2(.7 \%)$ & $3(1 \%)$ & \multirow[t]{6}{*}{$\mathrm{F}=6.8, \mathrm{df}=5, p<.001$} \\
\hline High school & $79(28 \%)$ & $131(43.5 \%)$ & \\
\hline Undergraduate & $79(28 \%)$ & $68(22.6 \%)$ & \\
\hline Degree, trade, or certificate & $78(27.7 \%)$ & $71(23.6 \%)$ & \\
\hline Master or doctorate & $42(14.9 \%)$ & $16(5.3 \%)$ & \\
\hline Other & $2(.7 \%)$ & $12(4 \%)$ & \\
\hline \multicolumn{4}{|l|}{ Work Status } \\
\hline Full time & $140(49.6 \%)$ & 89 (29.6\%) & \multirow[t]{6}{*}{$\mathrm{F}=12.816, \mathrm{df}=5, p<.001$} \\
\hline Part time & $50(17.7 \%)$ & 35 (11.6\%) & \\
\hline Casual & $17(6 \%)$ & $30(10 \%)$ & \\
\hline Student & $44(15.6 \%)$ & $41(13.6 \%)$ & \\
\hline Unemployed & $25(8.9 \%)$ & $88(29.2 \%)$ & \\
\hline Not applicable & $6(2.1 \%)$ & $18(6 \%)$ & \\
\hline \multicolumn{4}{|l|}{ Income } \\
\hline$<$ AUD\$18,200 & 49 (17.4\%) & $108(35.9 \%)$ & \multirow[t]{6}{*}{$\mathrm{F}=13.142, \mathrm{df}=5, p<.001$} \\
\hline$\$ 18,200-\$ 37,000$ & $36(12.8 \%)$ & $58(19.3 \%)$ & \\
\hline$\$ 37,001-\$ 87,000$ & $107(37.9 \%)$ & $86(28.6 \%)$ & \\
\hline$\$ 87,001-\$ 180,000$ & $45(16 \%)$ & $12(4 \%)$ & \\
\hline$>\$ 180,00$ & $16(5.7 \%)$ & $2(.7 \%)$ & \\
\hline Undisclosed & $29(10.3 \%)$ & $35(11.6 \%)$ & \\
\hline
\end{tabular}

consciousness $(\mathrm{t}=2.857, \mathrm{df}=581, p<.01)$; the PHI group has higher health consciousness $(\mathrm{M}=4.05, \mathrm{SD}=.68, \mathrm{SE}=$ .041 ) and those without PHI had lower health consciousness $(\mathrm{M}=3.88, \mathrm{SD}=.78, \mathrm{SE}=.045)$. The null hypothesis for $\mathrm{H} 1$ is rejected.

$\mathrm{H} 2$ examined the two groups' differences in terms of their perceptual variables: problem recognition $(t=3.37$, $\mathrm{df}=581, p<.001)$, constraint recognition $(\mathrm{t}=11.86, \mathrm{df}=$ $581, p<.001)$, involvement recognition $(\mathrm{t}=11.2, \mathrm{df}=581$, $p<.001)$ and past experiences $(\mathrm{t}=9.56, \mathrm{df}=579, p<.001)$. The null hypothesis for $\mathrm{H} 2$ is rejected. The two groups also differed in perceived value $(\mathrm{t}=.234, \mathrm{df}=576, p<.05)$ and trust $(\mathrm{t}=4.72, \mathrm{df}=574, p<.001)$, so the null hypotheses for $\mathrm{H} 3$ and $\mathrm{H} 4$ were rejected. The null hypothesis for $\mathrm{H} 5$ was also rejected as the two groups differed in their attitude toward PHI $(\mathrm{t}=12.87, \mathrm{df}=581, p<.001)$.
Results from Structural Equation Modelling are shown in Fig. 2 for the group without PHI. For the group without PHI, problem recognition $(\beta=.388, p<.001)$, involvement recognition $(\beta=.320, p<.001)$, perceived value $(\beta=-.184, p<.001)$ and trust $(\beta=.140, p<.001)$ were all associated with attitude, but the null hypothesis for $\mathrm{H} 6 \mathrm{~b}$ failed to be rejected as constraint recognition had no relationships with attitude. Past experiences $(\beta=$ $.186, p<.001)$ and attitude $(\beta=.482, p=.024)$ positively predicted intention to enrol. Health consciousness was found to have a significant relationship with intention to enrol $(\beta=.154, p<.001)$ and was thus, added as a control variable to the study. The model fit was acceptable $\left(\chi^{2}=17.607, \mathrm{df}=8, \chi^{2} / \mathrm{df}=2.201, p=<.05, \mathrm{CFI}=.990\right.$, RMSEA $=.063$, SRMR $=.0210)$ based on $\mathrm{Hu}$ and Bentler's (1999) cut-off criteria for fit indices $\left(\mathrm{X}^{2} / \mathrm{df}<3\right.$, 
Table 2 Factor loadings, mean, standard deviation, and standard error of the mean for each survey item ( $a=$ Cronbach's alpha, $\mathrm{KMO}=$ Kaiser-Meyer-Olkin, $\mathrm{M}=$ mean, SD = standard deviation, SE = standard error)

\begin{tabular}{|c|c|c|c|c|c|}
\hline Variable & Survey Item & $\begin{array}{l}\text { Factor } \\
\text { Loadings }\end{array}$ & Mean & SD & SE \\
\hline \multirow{5}{*}{$\begin{array}{l}\text { Health consciousness } \\
\mathbf{a}=.757 \\
\mathrm{KMO}=.773 \\
\text { Variance explained = } \\
61.53 \%\end{array}$} & I do everything I can to stay healthy. & Removed & & & \\
\hline & Living life in best possible health is important to me. & .803 & 3.96 & .892 & .037 \\
\hline & I actively try to prevent diseases and illnesses. & .699 & 3.89 & .912 & .038 \\
\hline & Eating right, exercising, and taking preventive measures will keep me healthy for life. & .634 & 4.03 & .875 & .036 \\
\hline & My health depends on how well I take care of myself. & Removed & & & \\
\hline \multirow{4}{*}{$\begin{array}{l}\text { Problem recognition } \\
\mathbf{a}=.881 \\
\mathrm{KMO}=.804 \\
\text { Variance explained }= \\
73.76 \%\end{array}$} & I think not having private health insurance is a problem. & .839 & 3.13 & 1.172 & .049 \\
\hline & I am concerned about those who do not have private health insurance. & .848 & 2.86 & 1.182 & .049 \\
\hline & $\begin{array}{l}\text { Something needs to be done to encourage Australians to purchase private health } \\
\text { insurance. }\end{array}$ & .783 & 3.23 & 1.152 & .048 \\
\hline & I recognise the importance of having private health insurance. & .752 & 3.45 & 1.167 & .048 \\
\hline \multirow{4}{*}{$\begin{array}{l}\text { Constraint recognition } \\
\mathbf{a}=.743 \\
\mathrm{KMO}=.782 \\
\text { Variance explained = } \\
63.31 \%\end{array}$} & I feel capable of protecting myself by having private health insurance. & Removed & & & \\
\hline & There are no barriers stopping me from having private health insurance. & .682 & 2.93 & 1.29 & .054 \\
\hline & I feel confident about choosing the right private health insurance plan for myself. & .846 & 3.17 & 1.17 & .048 \\
\hline & It is easy to purchase private health insurance. & .705 & 3.25 & 1.15 & .048 \\
\hline \multirow{4}{*}{$\begin{array}{l}\text { Involvement } \\
\text { recognition } \\
\mathbf{a}=.910 \\
\mathrm{KMO}=.803 \\
\text { Variance explained = } \\
78.75 \%\end{array}$} & Not having private health insurance can affect me personally. & .803 & 3.29 & 1.145 & .047 \\
\hline & $\begin{array}{l}\text { Not having private health insurance can have consequences for me and those I care } \\
\text { about. }\end{array}$ & .799 & 3.32 & 1.147 & .048 \\
\hline & Not having private health insurance can threaten my health. & .904 & 2.98 & 1.193 & .049 \\
\hline & My health can be affected if I do not have private health insurance. & .871 & 2.94 & 1.211 & .050 \\
\hline \multirow{4}{*}{$\begin{array}{l}\text { Past Experiences } \\
\mathbf{a}=.871 \\
\mathrm{KMO}=.768 \\
\text { Variance explained }= \\
72.09 \%\end{array}$} & My health can be affected if I do not have private health insurance. & .853 & 2.46 & 1.314 & .054 \\
\hline & Not having private health insurance has caused me problems in the past. & .816 & 2.58 & 1.288 & .053 \\
\hline & I have dealt with problems caused by not having private health insurance in the past. & .782 & 2.83 & 1.299 & .054 \\
\hline & My past experiences have taught me the importance of private health insurance. & .712 & 2.73 & 1.290 & .053 \\
\hline \multirow{6}{*}{$\begin{array}{l}\text { Trust } \\
\mathbf{a}=.931 \\
\text { KMO }=.904 \\
\text { Variance explained }= \\
74.4 \%\end{array}$} & Insurance companies treat their customers fairly and justly. & .931 & 3.04 & 1.05 & .043 \\
\hline & $\begin{array}{l}\text { Whenever insurance companies make important decisions, they are concerned about } \\
\text { their customers. }\end{array}$ & .884 & 2.86 & 1.12 & .046 \\
\hline & Insurance companies can be relied on to keep their promises for customers. & .886 & 2.93 & 1.109 & .046 \\
\hline & $\begin{array}{l}\text { Insurance companies take the opinions of their customers into account when making } \\
\text { decisions. }\end{array}$ & .857 & 2.97 & 1.122 & .046 \\
\hline & $\begin{array}{l}\text { Insurance companies have the ability to accomplish when they say they will do for } \\
\text { their customers. }\end{array}$ & .687 & 3.21 & 1.045 & .043 \\
\hline & Insurance companies will do what they say they will do for their customers. & .841 & 2.99 & 1.045 & .043 \\
\hline \multirow{4}{*}{$\begin{array}{l}\text { Attitude } \\
\mathbf{a}=.817 \\
\mathrm{KMO}=.693 \\
\text { Variance explained }= \\
73.43 \%\end{array}$} & It is good to have private health insurance. & .709 & 3.74 & 1.015 & .042 \\
\hline & It is dangerous not to have private health insurance. & .724 & 2.98 & 1.181 & .049 \\
\hline & It is worth spending money on private health insurance. & .898 & 3.26 & 1.139 & .047 \\
\hline & It is worth ensuring that private health insurance has adequate coverage. & Removed & & & \\
\hline
\end{tabular}

CFI > .95, RMSEA<.06). The model predicts $40.6 \%$ of individuals' intention to enrol.

Results from Structural Equation Modelling are shown in Fig. 3 for the group with PHI. Problem recognition $(\beta=.396, p<.001)$, involvement recognition $(\beta=.197$, $p<.001)$, perceived value $(\beta=-.106, p<.05)$ and trust $(\beta=.221, p<.001)$ were all associated with attitude, but the null hypothesis for $\mathrm{H} 6 \mathrm{~b}$ also failed to be rejected for this group as constraint recognition had no relationships with attitude. Past experience had no relationship with intention to cancel but attitude $(\beta=-.327, p<.001)$ had a negative relationship with intention to cancel. Health consciousness was positively associated with attitude $(\beta=.111, \quad p<.01)$ and gender was associated with intention to cancel $(\beta=.193, p<.001)$. Females were less likely to cancel PHI. These variables were added to the 
Table 3 Results from the hypotheses tested

\begin{tabular}{|c|c|c|c|c|c|}
\hline Hypothesis & Variable & Estimate & df & $p$-value & Result \\
\hline \multicolumn{6}{|c|}{ Comparisons between those with and without PHI } \\
\hline $\mathrm{H} 1 \mathrm{O}$ & Health consciousness & $t=2.857$ & 581 & .004 & rejected \\
\hline \multirow[t]{4}{*}{$\mathrm{H} 2 \mathrm{O}$} & (a) Problem recognition & $t=3.37$ & 581 & .000 & rejected \\
\hline & (b) Constraint recognition & $t=11.86$ & 581 & .000 & rejected \\
\hline & (c) Involvement recognition & $t=11.20$ & 581 & .000 & rejected \\
\hline & (d) Past experience & $t=9.56$ & 579 & .000 & rejected \\
\hline $\mathrm{H} 30$ & Perceived value & $t=-.234$ & 576 & .020 & rejected \\
\hline $\mathrm{H} 4 \mathrm{O}$ & Trust & $t=4.72$ & 574 & .000 & rejected \\
\hline $\mathrm{H} 5 \mathrm{O}$ & Attitude & $t=12.87$ & 581 & .000 & rejected \\
\hline \multicolumn{6}{|c|}{ Hypotheses tested for those without PHI } \\
\hline \multirow[t]{5}{*}{$\mathrm{H} 6 \mathrm{O}$} & (a) Problem recognition - Attitude & $\beta=.388$ & - & .000 & rejected \\
\hline & (b) Constraint recognition - Attitude & $\beta=.006$ & - & .881 & fail to be rejected \\
\hline & (c) Involvement recognition - Attitude & $\beta=.320$ & - & .000 & rejected \\
\hline & (d) Percieved value - Attitude & $\beta=-.184$ & - & .000 & rejected \\
\hline & (e) Trust - Attitude & $\beta=.140$ & - & .000 & rejected \\
\hline H7o & Past experience - intention to enrol & $\beta=.186$ & - & .000 & rejected \\
\hline $\mathrm{H} 8 \mathrm{O}$ & Attitude - intention to enrol & $\beta=.482$ & - & .000 & rejected \\
\hline \multicolumn{6}{|c|}{ Hypotheses tested for those with PHI } \\
\hline \multirow[t]{5}{*}{$\mathrm{H} 6 \mathrm{O}$} & (a) Problem recognition - Attitude & $\beta=.396$ & - & .000 & rejected \\
\hline & (b) Constraint recognition - Attitude & $\beta=.054$ & - & .283 & fail to be rejected \\
\hline & (c) Involvement recognition - Attitude & $\beta=.197$ & - & .000 & rejected \\
\hline & (d) Percieved value - Attitude & $\beta=-.106$ & - & .015 & rejected \\
\hline & (e) Trust - Attitude & $\beta=.221$ & - & .000 & rejected \\
\hline $\mathrm{H} 7 \mathrm{O}$ & Past experience - intention to cancel & $\beta=.082$ & - & .155 & fail to be rejected \\
\hline $\mathrm{H} 8 \mathrm{O}$ & Attitude - intention to cancel & $B=-.327$ & - & .000 & rejected \\
\hline
\end{tabular}

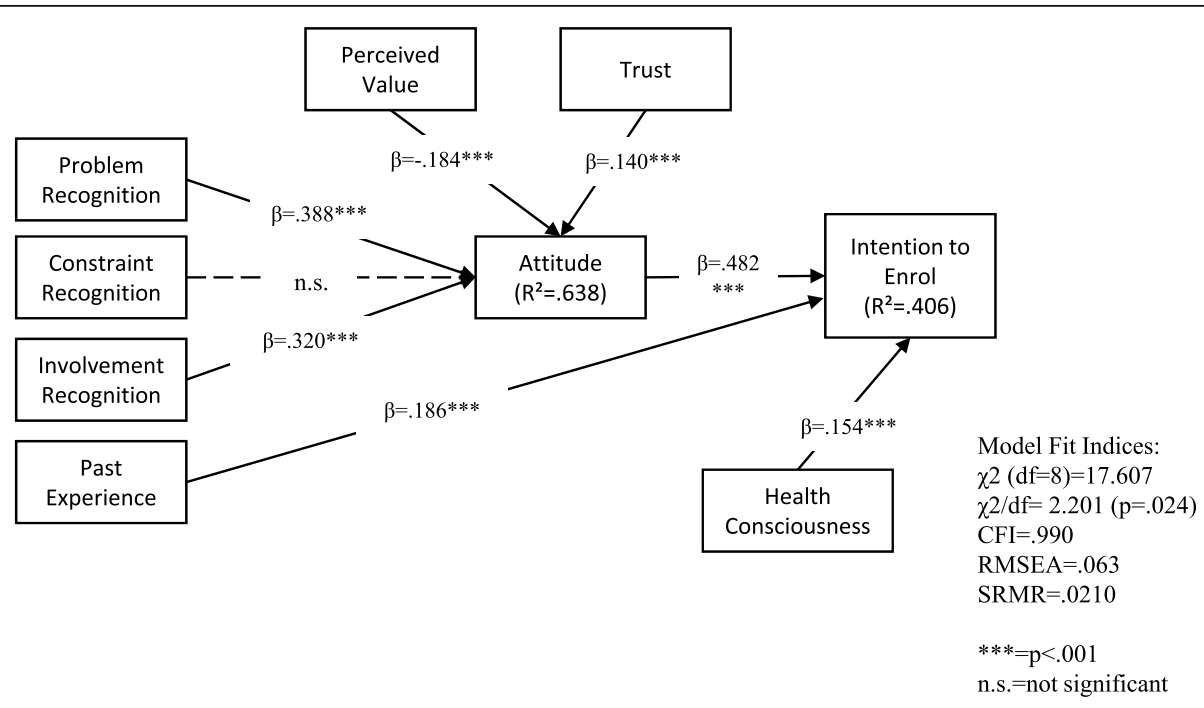

Fig. 2 Structural model for the group without PHI 


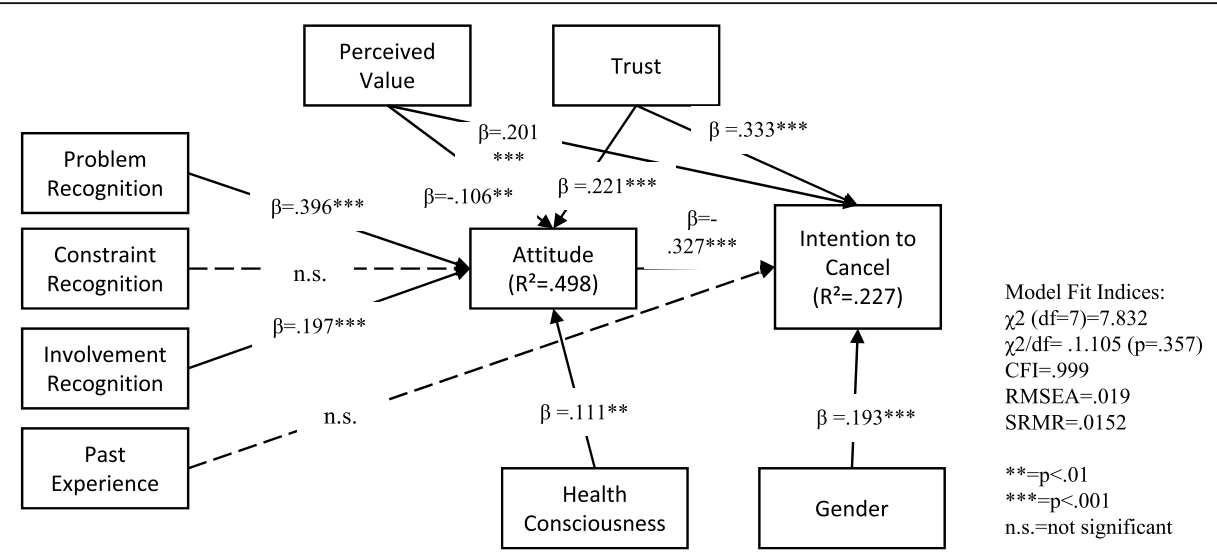

Fig. 3 Structural model for the group with PHI

model as control variables. The model fit was acceptable $(\mathrm{X} 2=7.832, \mathrm{df}=7, \mathrm{X} 2 / \mathrm{df}=1.105, p=.357, \quad \mathrm{CFI}=.999$, RMSEA $=.019$, SRMR $=.0152$ ) based on $\mathrm{Hu}$ and Bentler's (1999) cut-off criteria for fit indices $(x 2 / \mathrm{df}<3$, CFI $>.95$, RMSEA $<.06$ ). The model predicts $22.7 \%$ of individuals' intention to cancel PHI.

\section{Discussion}

The findings from this study provide a more holistic picture of the differing motivational factors and barriers between young adults with PHI and those without PHI beyond the economic perspective. Reflecting on the differences between the two groups, it is of note that those with PHI are generally higher in health consciousness which corresponds to existing findings [24] that healthier individuals are more risk averse. This study also identified perceived value and trust in insurance companies as significant factors affecting attitude towards PHI for both groups. Combined these findings point to the need to not only use demographic variables (e.g., socioeconomic factors like education and income) to understand young adults' intentions to enrol or cancel PHI. As highlighted in the models above, health consciousness, perceptual variables, perceived value and trust also should be considered when exploring this decisionmaking process.

This study has examined the motivational factors that affected young adults' attitude and behavioural intentions towards PHI. The findings have several implications. In comparing young adults with and without PHI, this study found that there are demographic differences (e.g., education, work status and income) that affected attitude and intention that policymakers cannot easily influence. But the differences in other factors including health consciousness, problem recognition, involvement recognition and constraint recognition value can be managed through communication intervention campaigns to promote health beliefs, healthy activities, and benefits of PHI. As for trust and perceived value, it requires responses from PHI providers. On one hand, policies can be adjusted and communication interventions can be implemented with intent to increase the attractiveness of PHI. On the other hand, the lack of trust in PHI providers can negatively affect attitude.

The structural model for the group without PHI shows that past experiences and health consciousness directly increase intention to enrol, whereas problem recognition, involvement recognition, trust and perceived value affect attitude. Policymakers and PHI providers should consider how the promotion of health consciousness amongst the population could also improve PHI uptake. On the other hand, the structural model for the group with PHI shows that past experiences do not affect intention to cancel but gender does. Males show higher intention to cancel than females. With females identified as being more risk-averse, their influential roles in affecting other household members (e.g., males) decisions on PHI could be significant. Lastly, from a policy perspective, although existing studies found that policy changes (e.g., rebates and tax implications) are significant in predicting PHI uptake, it is noteworthy that these policies may not entirely benefit young adults. For example, the Lifetime Health Cover Loading in Australia does not apply to those under the age of 31 [10]. Thus, factors that contribute to an individual's intention to enrol and intention to cancel should be explored more comprehensively. Perceptions of the other significant factors (including problem recognition, involvement recognition, trust and perceived value) can be improved with investments in communication interventions and organisational actions. 


\section{Limitations}

As in any research, there are limitations in the study. First, this dataset is cross-sectional and was collected in April 2018. Future studies should consider collecting data at two different times to explore how environmental factors such as policy changes or changes in the economic environment may affect the hypotheses tested. Second, two variables, namely perceived value and behavioural intention, were measured using one item. To ensure reliability and validity, future studies should use multiple items. Third, while this study has examined a number of factors that affected decisions, there could be other factors, such as parental influence, which have not been explored. Although the model for the group without PHI can explain $40.6 \%$ of respondents' intention to enrol, the model for the group with PHI only explains $22.7 \%$ of respondents' intention to cancel. As such, there could be other determinants explaining the intention to cancel. Lastly, because the sample was representative of the Australian population by the selected age range, this study was not able to identify whether age was related to PHI status. Future studies could investigate whether the cost of PHI could be a barrier for younger adults because of their relative income. These studies could consider price floors and ceilings that are perceived as affordable by young adults and older adults, noting that that PHI premium increases are regulated by PHI insurance laws in Australia.

\section{Conclusion}

Although the Australian government has implemented economic incentives to encourage PHI uptake, many of these incentives do not benefit young adults. Young adults aged 18 to 30 are critical to improving the risk pool of PHI, but the industry has continued to face the challenge of failing membership among young adults. This has raised concerns about the worsening affordability of PHI and the long-term sustainability of the industry. While existing studies have mostly focussed the effectiveness of economic incentives in improving uptake, this study proposed that for young adults as a demographic group, it is important to understand the motivational factors and barriers to PHI beyond the economic perspective. By comparing the differences between insured and uninsured young adults, this study found that factors including education, work status and income could affect PHI uptake. As these factors cannot be changed by policymakers, the findings proposed that promoting health consciousness amongst young adults and improving trust in insurance companies and perceived value could potentially improve PHI uptake and reduce PHI dropout amongst young adults.
Abbreviation

PHI: Private Health Insurance

\section{Supplementary Information}

The online version contains supplementary material available at https://doi. org/10.1186/s12913-021-06249-y.

Additional file 1.

Acknowledgements

Not applicable.

\section{Authors' contributions}

All authors contributed to the study design. LT analysed the datasets and prepared the first draft of the manuscript. ET, AM, and IL made substantial revisions to the manuscript prior to its submission. All authors have read and approved the manuscript.

\section{Funding}

The authors did not receive funding for this study.

Availability of data and materials

All data generated or analysed during this study are included in this published article.

\section{Declarations}

Ethics approval and consent to participate

This study was approved by the Queensland University of Technology's Ethics Committee (1800000308). Prior to participating in the survey, respondents were instructed to read a Participant Information Sheet before indicating whether they consented to participate.

Consent for publication

Not applicable

Competing interests

There are no competing interests.

\section{Author details}

${ }^{1}$ School of Advertising, Marketing and Public Relations, Queensland University of Technology, 2 George Street, Brisbane, QLD 4000, Australia. ${ }^{2}$ QUT Business School, Queensland University of Technology, 2 George Street, Brisbane, QLD 4000, Australia.

Received: 25 August 2020 Accepted: 7 March 2021

Published online: 19 March 2021

References

1. McCauley D. Private health insurers want rule changes to entice young members. The Sydney Morning Herald. 2020; https://www.smh.com.au/ politics/federal/private-health-insurers-want-rule-changes-to-entice-youngermembers-20200623-p5559j.html. Accessed 20 Aug 2020.

2. Paez KA, Mallery CJ, Noel H, Pugliese C, MCSorley VE, Lucado JL, et al. Development of the health insurance literacy measure (HILM): conceptualizing and measuring consumer ability to choose and use private health insurance. J Health Commun. 2014;19(sup2):225-39. https://doi.org/1 0.1080/10810730.2014.936568.

3. Loewenstein G, Friedman JY, McGill B, Ahmad S, Linck S, Sinkula S, Beshears J, Choi JJ, Kolstad J, Laibson D, Madrian BC, List JA, Volpp KG. Consumers' misunderstanding of health insurance. J Health Econ. 2013;32(5):850-62. https://doi.org/10.1016/j.jhealeco.2013.04.004.

4. Sowa PM, Kault S, Byrnes J, Ng SK, Comans T, Scuffham PA. Private health insurance incentives in Australia: in search of cost-effective adjustments. Appl Health Econ Health Policy. 2018;16(1):31-41. https://doi.org/10.1007/s4 0258-017-0338-6.

5. Australian Prudential Regulation Authority. Quarterly private health insurance statistics. 2020. https://www.apra.gov.au/sites/default/files/202005/QuarterlyprivatehealthinsurancestatisticsMarch2020.pdf. 
6. Duckett S. Changes to lure young people into private health insurance won't slow increase in premiums. The Conversation. 2017; https://theconversation. com/changes-to-lure-young-people-into-private-health-insurance-wont-slowincrease-in-premiums-85663. Accessed 20 Aug 2020.

7. Robb K. Why cancelling your private health insurance could have unintended consequences. ABC News. 2020. https://www.abc.net.au/news/2 020-01-20/cancelling-private-health-insurance-could-backfire-expert-says/11 878140. Accessed 20 Aug 2020.

8. Fox H, Topp SM, Callander E, Lindsay D. A review of the impact of financing mechanisms on maternal health care in Australia. BMC Public Health. 2019; 19(1):1540. https://doi.org/10.1186/s12889-019-7850-6.

9. Palangkaraya A, Yong J, Webster E, Dawkins P. The income distributive implications of recent private health insurance policy reforms in Australia. Eur J Health Econ. 2009;10(2):135-48. https://doi.org/10.1007/s10198-0080111-8.

10. Palangkaraya A, Yong J. How effective is "lifetime health cover" in raising private health insurance coverage in Australia? An assessment using regression discontinuity. Appl Econ. 2007;39(11):1361-74. https://doi.org/1 $0.1080 / 00036840500486532$.

11. Butler B. More trouble for private health funds after financial markets crashed due to coranavirus. The Guardian. 2020. https://www.theguardian. com/australianews/2020/may/19/more-trouble-for-private-health-funds-asfinancial-markets-crash-due-to-coronavirus. Accessed 20 Aug 2020.

12. Buchmueller TC, Fiebig DG, Jones G, Savage E. Preference heterogeneity and selection in private health insurance: the case of Australia. J Health Econ. 2013;32(5):757-67. https://doi.org/10.1016/j.jhealeco.2013.05.001.

13. Harley K, Willis K, Gabe J, Short SD, Collyer F, Natalier K, Calnan M. Constructing health consumers: private health insurance discourses in Australia and the United Kingdom. Health Sociol Rev. 2011;20(3):306-20. https://doi.org/10.5172/hesr.2011.20.3.306.

14. Natalier K, Willis K. Taking responsibility or averting risk? A socio-cultural approach to risk and trust in private health insurance decisions. Health Risk Soc. 2008;10(4):399-411. https://doi.org/10.1080/13698570802167413.

15. Cantiello J, Fottler MD, Oetjen D, Zhang NJ. The impact of demographic and perceptual variables on a young adult's decision to be covered by private health insurance. BMC Health Serv Res. 2015;15(1):195. https://doi. org/10.1186/s12913-015-0848-6.

16. Iversen AC, Kraft P. Does socio-economic status and health consciousness influence how women respond to health related messages in media? Health Educ Res. 2006;21(5):601-10. https://doi.org/10.1093/her/cyl014

17. Newsom JT, McFarland BH, Kaplan MS, Huguet N, Zani B. The health consciousness myth: implications of the near independence of major health behaviors in the north American population. Soc Sci Med. 2005;60(2):433-7. https://doi.org/10.1016/j.socscimed.2004.05.015.

18. Thompson SN, Chambers JW. African self-consciousness and healthpromoting behaviors among african american college students. J Black Psychol. 2000;26(3):330-45. https://doi.org/10.1177/0095798400026003005.

19. Bediako SK, Kwate NOA, Rucker R. Dietary behavior among African Americans: Assessing cultural identity and health consciousness. Ethnicity and Disease. 2004;14(4):527-32.

20. Mai R, Hoffmann S. Taste lovers versus nutrition fact seekers: how health consciousness and self-efficacy determine the way consumers choose food products. J Consum Behav. 2012;11(4):316-28. https://doi.org/10.1002/cb.1390.

21. Jayanti RK, Burns AC. The antecedents of preventive health care behavior: an empirical study. J Acad Mark Sci. 1998;26(1):6-15. https://doi.org/10.1177/ 0092070398261002

22. Dutta-Bergman MJ. Primary sources of health information: comparisons in the domain of health attitudes, health cognitions, and health behaviors. Health Commun. 2004;16(3):273-88. https://doi.org/10.1207/S15327027HC1603_1.

23. Moorman C, Matulich E. A model of consumers' preventative health behaviors: The role of health motivation and health ability. J Consum Res. 1993;20(2):208-28

24. Schneider P. Why should the poor insure? Theories of decision-making in the context of health insurance. Health Policy Plan. 2004;19(6):349-55. https://doi.org/10.1093/heapol/czh050.

25. Grunig JE. Constructing public relations theory and practice. In: Dervin B, Chaffee $S$, Foreman-Wernet $L$, editors. Communication, another kind of horse race: Essays honoring Richard F. Carter. Creskill: Hampton Press; 2003. p. 85-115.

26. Kim J-N, Grunig JE. Problem solving and communicative action: a situational theory of problem solving. J Commun. 2011;61(1):120-49. https://doi.org/1 0.1111/j.1460-2466.2010.01529.x.
27. Cameron GT, Yang J. Effect of support and personal distance on the definition of key publics for the issue of AIDS. Journal Q. 1991;68(4):620-9. https://doi.org/10.1177/107769909106800402.

28. Toledano M, Riches M, Waddingham J, McKeever BW. From awareness to advocacy: understanding nonprofit communication, participation, and support. J Public Relat Res. 2013;25:307-28. https://doi.org/10.1002/nvsm.

29. Sha B-L. Cultural identity in the segmentation of publics: an emerging theory of intercultural public relations. J Public Relat Res. 2006;18(1):45-65. https://doi.org/10.1207/s1532754xjprr1801_3.

30. Weberling B, Waters RD. Gauging the public's preparedness for mobile public relations: the "text for Haiti" campaign. Public Relat Rev. 2012;38(1): 51-5. https://doi.org/10.1016/j.pubrev.2011.11.005.

31. Zheng Y, McKeever BW. Communicating to improve health: using theory to improve fundraising for health-related news. Nonprofit Volunt Sect Q. 2016; 45(6):1276-96. https://doi.org/10.1177/0899764016649694.

32. Kim J-N, Grunig JE, Ni L. Reconceptualizing the communicative action of publics: acquisition, selection, and transmission of information in problematic situations. Int J Strateg Commun. 2010;4(2):126-54. https://doi.org/10.1080/15531181003701913.

33. Kim J-N, Shen H, Morgan SE. Information behaviors and problem chain recognition effect: applying situational theory of problem solving in organ donation issues. Health Commun. 2011;26(2):171-84. https://doi.org/10.1 080/10410236.2010.544282.

34. Robson A, Paolucci F. Private health insurance incentives in Australia: the effects of recent changes to price carrots and income sticks. Geneva Pap Risk Insur Issues Pract. 2012;37(4):725-44. https://doi.org/10.1057/gpp.2012.38.

35. Ki E-J, Hon LC. Testing the linkages among the organization-public relationship and attitude and behavioral intentions. J Public Relat Res. 2007; 19(1):1-23. https://doi.org/10.1207/s1532754xjprr1901_1.

36. Sirdeshmukh D, Singh J, Sabol B. Consumer trust, value, and loyalty in relational exchanges. J Mark. 2002;66(1):15-37. https://doi.org/10.1509/jmkg.66.1.15.18449.

37. Ranaweera C, Prabhu J. The influence of satisfaction, trust and switching barriers on customer retention in a continuous purchasing setting. Int J Serv Ind Manag. 2003;14(4):374-95. https://doi.org/10.1108/09564230310489231.

38. Walsh G, Mitchell V-W, Jackson PR, Beatty SE. Examining the antecedents and consequences of corporate reputation: a customer perspective. $\mathrm{Br}$ J Manag. 2009;20(2):187-203. https://doi.org/10.1111/j.1467-8551.2007.00557.x.

39. Wei J, Hansen A, Zhang Y, Li H, Liu Q, Sun Y, Bi P. Perception, attitude and behavior in relation to climate change: a survey among $C D C$ health professionals in Shanxi province, China. Environ Res. 2014;134:301-8. https:// doi.org/10.1016/j.envres.2014.08.006.

40. Ajzen I. The theory of planned behavior. Organ Behav Hum Decis Process. 1991;50(2):179-211. https://doi.org/10.1016/0749-5978(91)90020-T.

41. Araújo LS, Wasley D, Perkins R, Atkins L, Redding E, Ginsborg J, et al. Fit to perform: An investigation of higher education music students' perceptions, attitudes, and behaviors toward health. Front Psychol. 2017;8(OCT):1-19.

42. Hon LC, Grunig JE. Guidelines for measuring relationships in public relations, 1999. http://www.aco.nato.int/resources/9/Conference2011/Guidelines_Mea suring Relationships[1].pdf.

43. Carpenter S. Ten Steps in scale development and reporting: a guide for researchers. Commun Methods Meas. 2018;12(1):25-44. https://doi.org/10.1 080/19312458.2017.1396583.

44. Park HS, Dailey R, Lemus D. The use of exploratory factor analysis and principal component analysis in communication research. Hum Commun Res. 2002;28(4):562-77. https://doi.org/10.1111/j.1468-2958.2002.tb00824.x.

45. Williams B, Onsman A, Brown T. Exploratory factor analysis: A five-step guide for novices. J Emerg Prim Health Care. 1996;19(May):42-50.

\section{Publisher's Note}

Springer Nature remains neutral with regard to jurisdictional claims in published maps and institutional affiliations. 